\title{
Monitoring System of Tianjin Municipal Pumping Station Based on Internet of Things Technology
}

\author{
Li-Wei Wang ${ }^{1, ~ a ~ a n d ~ J i a n-Y u ~ L u ̈, b ~}$ \\ ${ }^{1}$ Tianjin Facilities Management Service Company, Tianjin 300456, China \\ ${ }^{2}$ Laboratory of Waterway Environmental Protection Technology, Tianjin Water Transport \\ Engineering Science Research Institute, Tianjin 300456, China \\ a418381743@qq.com, ${ }^{b} 18810993413 @ 163 . c o m$
}

\begin{abstract}
Keywords: Internet of Things, Configuration Software, PLC, GPRS, Municipal Drainage.
Abstract. Put forward the remote monitoring plan of pumping station by introducing the difficulties of the management and operation of the pumping station. The paper realized the transmission of running data and image at pumping station field equipment by using wireless communication technology. The paper introduced the main communication mode and the background frame of monitoring system. On the basis of introducing the characteristics and network principle of GPRS wireless communication technology, several communication technologies are compared while their advantages and disadvantages are analyzed. Combined with the actual characteristics of municipal pumping station and the development advantages of GPRS technology, the scheme and data transmission protocol which is most suitable for the project is selected. The main function, characteristics and workflow of the core module of remote control system GPRS DTU are explained in detail. The module can be used to realize remote transmission of equipment information in pumping station. The paper seriously analyze the PLC system selection, the network system establishment and the PLC control system establishment by the research of remote monitoring technology of Tianjin port municipal pumping station. Combined with the actual situation of pumping station operation, relevant solutions are put forward.
\end{abstract}

\section{Introduction}

Internet-of-things is a leading research topic in the area of communication and networking by now [1, 2]. It has wide application prospects in areas such as pattern recognition, positioning, monitoring, and management [3, 4]. At present, there are 12 municipal drainage pumping stations in the area of Tianjin port, distribute in North Port, South Port and East Port. There were disadvantages in the Tianjin Port's management of municipal drainage pumping station, such as staff shortage, poor management techniques and untimely monitoring. It is the use of Internet-of-Things technology that Tianjin Port could grasp, rapidly, centrally and precisely, the running data and monitoring images of the 12 municipal drainage pumping station in Tianjin port area, improved the level of pumping station management of Tianjin Port Group.

This topic put forward a remote monitoring and management project on the municipal drainage pumping stations of Tianjin Port Group through the use of Wincc, PLC, wireless communications and other industrial communication technologies. Through remotely collecting and transmitting operation data of pumping station equipment and monitoring images, Tianjin Port can really achieve remote monitoring and management of pumping stations in an efficient way. This project has been applied in the municipal drainage center of Tianjin port, obtaining a remote real-time monitor system which can offer the operation and image of the pumping stations [5,6]. It solves the problem of inadequate management staff and weak management means [7].

\section{Implementation and Application}

The field system of pumping station remote monitoring and controlling pump station is mainly composed of network communication system, PLC control system, instrument detection system and image monitoring system [8]. 


\section{Upper Computer}

The remote monitoring technology of Tianjin municipal pumping station cannot be achieved without the host computer. The host computer is located at the main control center, the sub control center and the field control station of the pump station. In the control system, the selected card Advantech industrial control computer, type IPC-4060, the type of industrial control computer equipped with temperature monitoring screen, LCD standard ATX power supply, intelligent temperature control fan, 7PCS PCI-E/PC full support line high expansion card. At the same time, the MCGS configuration software is installed in the industrial control computer to complete the management of the pumping station technological process, monitoring the operation condition of the pumping station, alarming and fault recording, etc.

\section{PLC}

PLC is the core equipment to realize the remote monitoring technology of Tianjin Municipal Pumping Station. To configure SIEMENS CPU315-2DP programmable controller, the CPU order number: 6ES7315-2AH14-0AB0 can be extended to up to 32 modules. To configure SIEMENS power module, model: PS307-5A, power output is DC24V/5A. It is intended to configure SIEMENS communication module CP343-1, which has two RJ45 interfaces, uses automatic sensing/automatic negotiation function, and can be connected to industrial Ethernet through automatic sensing of data transmission rate.

\section{Control Bus}

The connection of field devices is realized by PROFIBUS-DP technology, and the SIEMENS CPU315-2DP programmable controller is equipped with PROFIBUS-DP ports, which can realize high-speed information transmission between field devices and CPU315-2DP. PROFIBUS-DP technology can connect up to 126 sites.

\section{Selection of Distributed I/O}

To configure the distributed remote I/O module, the model is DI32 * DC24V, DO16 * DC24V/0.5A, AI8 * 16Bit. The analog input module and the digital output module need to be connected with the signal cable through the field bus to shorten the distance from the field signal to the CPU reduce the laying of communication cables and improve the construction efficiency.

\section{Network Communication System}

GPRS wireless network communication system is the key technology to realize the remote monitoring system of Tianjin municipal pumping station. The remote monitoring system is mainly through the site monitoring liquid level, flow, voltage data acquisition instrument, fieldbus connection through the I/O module, the information transmission equipment to the PLC, and then PLC will send the information to the DTU module, the information through the GPRS network to transmit the information to the host computer.

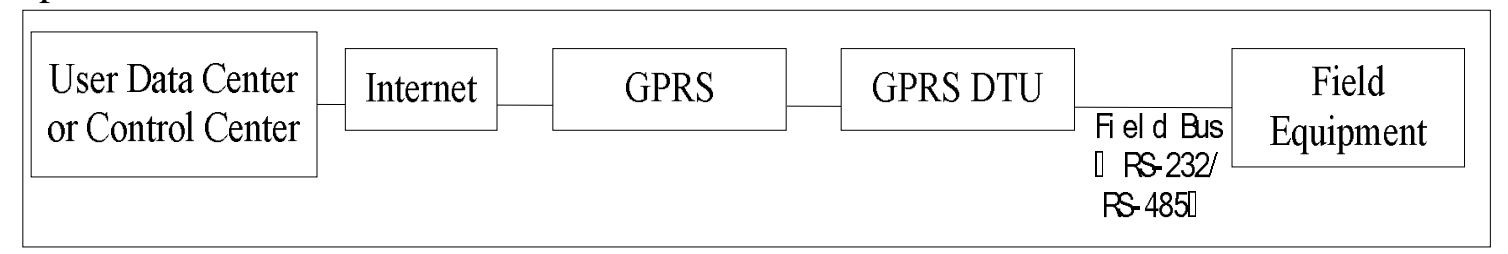

Fig. 1 Composition of GPRS remote monitoring 


\section{PLC Control System}

The PLC control system mainly collects the signals such as voltage and current from the field sensors, and transmits the information to the PLC through the $\mathrm{I} / \mathrm{O}$ module. The automatic control of the field equipment is carried out according to the pre-programmed procedures in CPU.

The pumping station adopts PLC (programmable logic controller) to control process parameters and power equipment for drainage process of detection, automatic control and interlock, and through the monitoring computer, real-time data process, image process parameters in the process of the implementation of pumping station and power equipment display and control parameters of the automatic control system set remote control, modify, overrun alarm, data storage etc.

\section{Automatic Control layer of PLC Pumping Station}

This system takes the central control room industrial control machine as the leading factor, transmits data through the network equipment, the sensor collects the field equipment data, and the PLC carries on the automatic control to the field equipment and the technological parameter. The pumping station is monitored through the main control center of the pumping station. The upper computer system can record the liquid level history curve, the flow history curve, the equipment operation status and so on. The operator on the main control center of the pumping station can remotely open the on-site equipment of the pumping station through the industrial computer.

Real time monitoring of scattered drainage sites, you can observe the operation of the equipment, easy to monitor and troubleshoot, and the following figure is a drainage site monitoring screen:

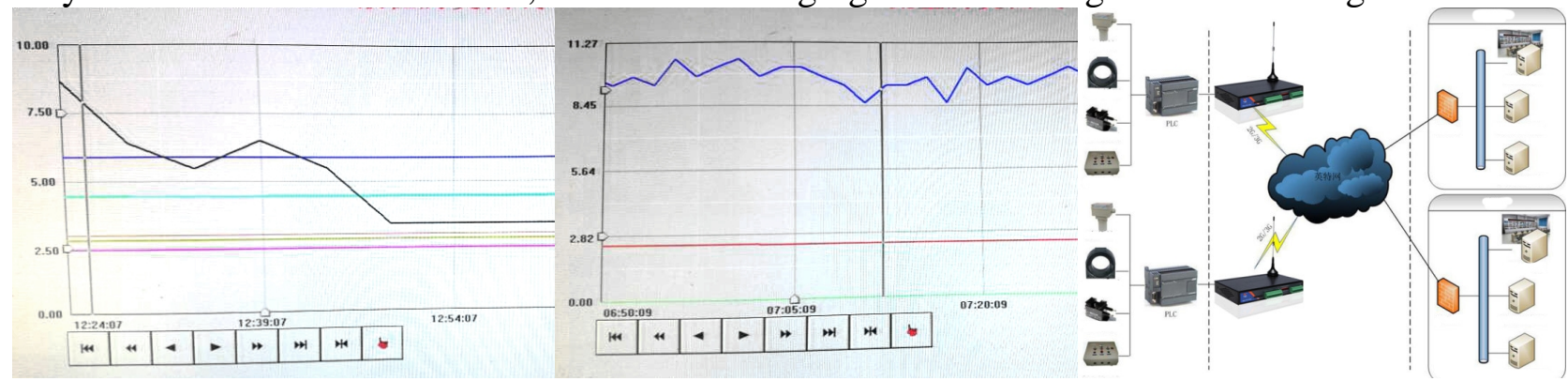

Fig. 2 Historical curves of level and discharge of remote drainage station

The formation of historical statements can be further analyzed and guided. The following figure is the water level and discharge of a drainage station.

\section{Conclusions}

The monitoring system realizes the remote monitoring of the pumping station in the Tianjin port area, and can operate stably, but it can be further improved in the following areas:

Wireless communications technology has been developing rapidly, similar monitoring systems should keep pace with the times, choose new, more stable, fast and reliable wireless communication technology or terminals to achieve remote data transmission.

There is a big gap between the theoretical transmission rates of 2. GPRS network and the actual application, the general can only reach $20-30 \mathrm{~kb} / \mathrm{s}$, and because the area of pumping station communication network signal instability, or transmission of a large amount of data, DTU will be dropped and the monitoring center phenomenon in communication, can be in programming to optimize the data transmission strategy, automatic redial rather than rely on the DTU function.

The system for multi-point to point communication structure, each sub control center level pumping station DTU only with the monitoring center for communication, try to design more point to have the following design, attempts to design between DTU terminal communication bottom station.

The data in this system is of some importance. In subsequent design, the data should be encrypted to ensure security. 
The monitoring system design of the configuration system can be concise and user-friendly improvement, so that managers or operators can see the operation of the entire system.

Introduction of GPS positioning technology, the position of each letter of the municipal pumping stations to the fusion server management software, introduced GIS system, introduced the map grid management technology, make the management more effective for remote monitoring, maintenance and upgrade pumping station to work.

\section{Acknowledgements}

This work was supported by the Research of "Study of foreign soil water retention, prevent salinization, heavy metal soil remediation, soil backfill and ecological restoration technique in land reclamation. (TKS150218).

\section{References}

[1] Microsoft.110 Completion Ports. msdn. microsoft. com/en-us/library/aa365198 (VS.85).aspx, 2009-02-3.

[2] Mark H Lucovsky, John D Vert, David N. Cutler. Input/output completion port queue data structures and methods for using same. United States Patent. 6223207. 2001-4-24.

[3] Bowles J.B. Fuzry logic prioritization of failure in a system failure mode, effects and criticality analysis [J]. Reliability Engineering and System Safety (1995), 50, p203-207.

[4] Bogarin A. Fault-tree analysis: a knowledge-engineering approach. Transaction on Reliability (1995), 44, p37-44.

[5] Xing L.M., Okrent D. The use of neural network and a prototype expert system in BWR ATWS accidents diagnosis [J]. Reliability Engineering and Safety (2004), 44, p361-365.

[6] Athinson T. Risk management for mining projects [J]. Mining Engineering (1999), 5: p131-136.

[7] Lee B.H. Locating monitoring stations in water distribution systems [J]. JAWWA (1991), 83 (7), p60-66.

[8] Johannes H. Andersen, Roger S. Powell. Implicit state-estimation technique for water network monitoring [J]. Urban Water (2002), 2, p123-130 